\title{
Rebamipide-containing Film Using Chitosan and HPMC for Oral Mucositis Induced by Cancer Chemotherapy
}

\author{
ISSEI TAKEUCHI ${ }^{1,2}$, CHIAKI TOGO ${ }^{1}$ and KIMIKO MAKINO ${ }^{1,2}$ \\ ${ }^{1}$ Faculty of Pharmaceutical Sciences, Tokyo University of Science, Chiba, Japan; \\ ${ }^{2}$ Center for Drug Delivery Research, Tokyo University of Science, Chiba, Japan
}

\begin{abstract}
Background/Aim: Oral mucositis is a significant side effect in cancer treatment. In this study, we aimed to develop a rebamipide-containing film using chitosan and hydroxypropyl methylcellulose (HPMC) to efficiently treat oral mucositis. Materials and Methods: A $0.1 \%(w / v)$ rebamipide aqueous solution, a $1.4 \%(\mathrm{w} / \mathrm{v})$ chitosan aqueous solution containing Pluronic ${ }^{\circledR}$ F-127, and a $1.0 \%$ (w/v) HPMC aqueous solution were mixed and dried using a square silicon frame to form a film. Cumulative release ratios of rebamipide from sample films were measured in a phosphate buffer ( $\mathrm{pH}$ 6.8) at $37^{\circ} \mathrm{C}$. Results: Chitosan suppressed the release of rebamipide from the film for up to $30 \mathrm{~min}$. HPMC contributed to the sustained release of the film over a relatively long period of time and the maintenance of its shape. Conclusion: The combined use of chitosan and HPMC is suitable as a base material for rebamipide-containing films.
\end{abstract}

Although chemotherapeutic agents play a central role in cancer treatment, side effects on highly proliferative tissues must be considered. Radiation therapy is also a useful treatment; however, it affects rapidly dividing cells and patients with chemoradiation therapy have an increased risk of treatment-related toxicity. Mucositis is one of the most common side effects of these treatments (1). Oral mucositis, which reduces the patient's quality of life and also affects compliance with anticancer therapy, is a major problem in most patients receiving high-dose chemotherapy and hematopoietic stem cell transplantation (2-4).

Recently, rebamipide, 2-(4-chlorobenzoylamino)-3-[2(1H)quinolinone-4-yl]-propionic acid, was studied as a therapeutic

Correspondence to: Kimiko Makino, Faculty of Pharmaceutical Sciences, Tokyo University of Science, 2641, Yamazaki, Noda, Chiba, 278-8510, Japan. Tel/Fax: +81 471213662, e-mail: makino@rs.noda.tus.ac.jp

Key Words: Chitosan, hydroxypropyl methylcellulose (HPMC), rebamipide, film, oral mucositis, swelling ratio. substance for oral mucositis induced by cancer chemotherapy (5). Since rebamipide has pharmacological effects such as promotion of prostaglandin $\left(\mathrm{PGE}_{2}\right)$ synthesis $(6)$, induction of mucus secretion (7), and free radical scavenging action (8), it is generally used for ulcer treatment, gastric mucosal protection, and dry eye treatment. In some hospitals, rebamipide gargle was actually used for the purpose of preventing and treating stomatitis, and examples of clinical research have been reported (9). However, with gargle, the residence time in the oral cavity is short, the local concentration of rebamipide in the oral mucosa is low, and the medicinal effect cannot be sufficiently exhibited (10). In this study, to solve the above-mentioned problems, a rebamipide-containing topical sustained-release film formulation for oral mucositis induced by cancer chemotherapy was developed for the purpose of improving oral residence time and locality. Effective treatment and improvement in patient's quality of life was expected by applying the film formulation to the inflamed area. We used chitosan, Pluronic ${ }^{\circledR}$ F-127, and hydroxypropyl methylcellulose (HPMC) as a base material of the film. Chitosan, which is biocompatible and has mucoadhesive properties and antibacterial action $(5,11)$, has been reported to contribute to sustained drug release (12). In addition, nanoparticle preparations utilizing the surface charge have been reported (13). Chitosan was used in this study with the expectation to slow release of rebamipide from the film. Pluronic ${ }^{\circledR}$ F-127 has been reported to increase the mucoadhesive properties of chitosan (14), and was used as a mucoadhesive enhancer. HPMC was used as a film-forming polymer. To evaluate the drug release behavior, the cumulative release ratio of rebamipide from the film was measured. It was expressed as the ratio of rebamipide released from the film divided by the amount of rebamipide initially contained in the film. The test was carried out with reference to the paddle method described in the Japanese Pharmacopoeia 17th edition. Moreover, the shape retention property of the film which affects its local effect and adhesiveness was evaluated using two types of swelling ratios. 
Table I. Composition of the mixture of rebamipide aqueous solution chitosan aqueous solution (containing 0.6\% (w/v) of Pluronic ${ }^{\circledR}$ F-127) and HPMC aqueous solution used for film preparation.

\begin{tabular}{lccc}
\hline Sample \# & $\begin{array}{c}0.1 \%(\mathrm{w} / \mathrm{v}) \\
\text { rebamipide } \\
\text { aqueous } \\
\text { solution }\end{array}$ & $\begin{array}{c}1.4 \%(\mathrm{w} / \mathrm{v}) \\
\text { chitosan } \\
\text { aqueous } \\
\text { solution }\end{array}$ & $\begin{array}{c}1.0 \%(\mathrm{w} / \mathrm{v}) \\
\text { HPMC } \\
\text { aqueous } \\
\text { solution }\end{array}$ \\
\hline 1 & 5.0 & 5.0 & 0.0 \\
2 & 5.0 & 4.0 & 1.0 \\
3 & 5.0 & 2.5 & 2.5 \\
4 & 5.0 & 2.0 & 3.0 \\
5 & 5.0 & 0.0 & 5.0 \\
\hline
\end{tabular}

\section{Materials and Methods}

Materials. Rebamipide $\left(\mathrm{C}_{19} \mathrm{H}_{15} \mathrm{ClN}_{2} \mathrm{O}_{4}\right.$, purity $\left.>99.5 \%\right)$ was purchased from LKT Laboratories, Inc. (St. Paul, MN, USA). Medium molecular weight chitosan and Pluronic ${ }^{\circledR}$ F-127 were purchased from Sigma-Aldrich Co. LLC. (St. Louis, MO, USA). HPMC, L-lactic acid $(\mathrm{CH} 3 \mathrm{CH}(\mathrm{OH}) \mathrm{COOH}$, purity $>85.0 \%)$, and sodium hydrogen carbonate $\left(\mathrm{NaHCO}_{3}\right.$, purity $\left.>99.7 \%\right)$ were purchased from Wako Pure Chemical Industries, Ltd. (Osaka, Japan). Other chemicals were of the highest reagent grade commercially available.

Preparation of rebamipide-containing film. One hundred milligrams of rebamipide were dissolved in $100 \mathrm{ml}$ of a $1.0 \%(\mathrm{w} / \mathrm{v})$ aqueous sodium bicarbonate solution to obtain a $0.1 \%(\mathrm{w} / \mathrm{v})$ rebamipide aqueous solution. A $1.4 \%(\mathrm{w} / \mathrm{v})$ chitosan aqueous solution was prepared by dissolving $1.4 \mathrm{~g}$ of chitosan and $0.6 \mathrm{~g}$ of Pluronic ${ }^{\circledR} \mathrm{F}$ 127 in $100 \mathrm{ml}$ of $5.0 \%(\mathrm{w} / \mathrm{v})$ L-lactic acid aqueous solution while heating at $60^{\circ} \mathrm{C}$. Pluronic ${ }^{\circledR} \mathrm{F}-127$ was used to prevent entrapment of bubbles into the film. Similarly, 1.0\% (w/v) HPMC aqueous solution was prepared by dissolving $1.0 \mathrm{~g}$ of HPMC in $100 \mathrm{ml}$ of Milli-Q water while heating at $60^{\circ} \mathrm{C}$. The prepared aqueous solutions were mixed as shown in Table I. The mixed solution was sonicated for 1 h using an ultrasonic bath (SUS-103, Shimadzu RIKA Corp., Tokyo, Japan) to remove internal bubbles. Then, $10.0 \mathrm{ml}$ of the mixed solution were poured into a square mold $(3.0 \mathrm{~cm} \times 3.0 \mathrm{~cm}$, thickness $3.0 \mathrm{~mm}$ ) prepared using a silicon rubber plate, and dried at room temperature overnight to produce a film.

Evaluation of physicochemical properties of rebamipide-containing film. The solid-state form of samples \#1-4 shown in Table I was confirmed using XRPD (RINT-Ultima 3, RIGAKU Co., Ltd., Akishima, Japan). Rebamipide powder was used as a control. The XRPD measurements were carried out in the standard measurement mode in the $2 \theta$ range from $5^{\circ}$ to $50^{\circ}$. The scan speed was $2^{\circ} / \mathrm{min}$ and the counting step was $0.02^{\circ}$. X-ray source was $\mathrm{CuK} \alpha$, the accelerating voltage was $40 \mathrm{kV}$, and the current was $40 \mathrm{~mA}$. Sample films were cut into a $2.0 \mathrm{~cm}$ square and filled in a glass sample plate (0.2 mm depth) (15).

Cumulative release ratios of rebamipide from samples \#1-4 shown in Table I were measured in a phosphate buffer $(\mathrm{pH}$ 6.8) at $37^{\circ} \mathrm{C}$. The sample films were sandwiched between a nylon mesh $(1.0 \mathrm{~mm}$ aperture $)$ and a watch glass $(7.0 \mathrm{~cm}$ inner diameter, $2.0 \mathrm{~mm}$
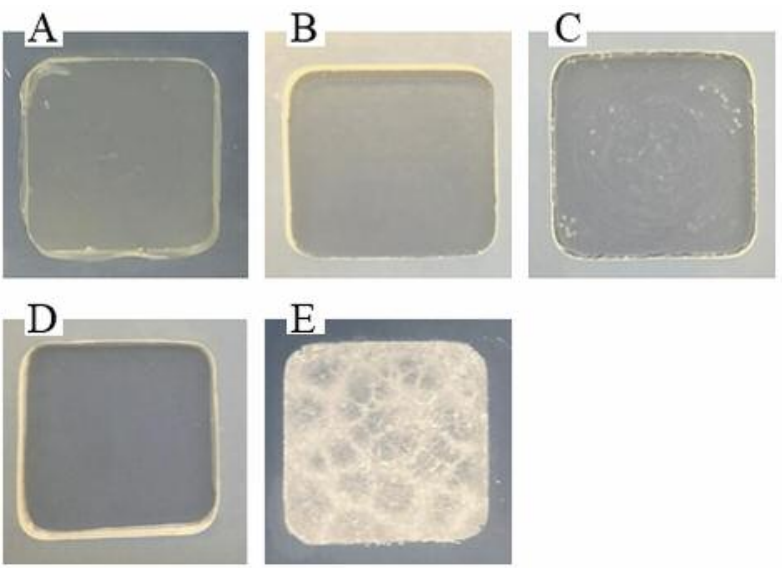

Figure 1. Appearance of the prepared film. (A) Sample \#1. (B) Sample \#2. (C) Sample \#3. (D) Sample \#4. (E) Sample \#5.

thickness) and submerged in a vessel. After 5, 15, 30, 60, 120, 240, and $360 \mathrm{~min}$ from the initiation of the test, $0.7 \mathrm{ml}$ of each sample were collected, and the cumulative release ratios of rebamipide from sample films at each time were calculated by measuring the amount of rebamipide using high-performance liquid chromatography (HPLC, SIL-20A prominence, SPD-20A prominence, LC-20AD prominence, CTO-10ASvp, DGU-20A3 prominence, Shimadzu Corp.) at $254 \mathrm{~nm}$ with an ODS column (STR ODS-II, size: $4.6 \mathrm{~mm}$ $\times 150 \mathrm{~mm}$, Shinwa Chemical Industries Ltd., Kyoto, Japan) (5).

To evaluate the influence of the ratio of the chitosan aqueous solution and the HPMC aqueous solution on the shape retention of the rebamipide-containing film, a swelling test was performed. Prior to the test, we measured the side length $\left(L_{\text {dry }}\right)$ and weight $\left(W_{\text {dry }}\right)$ of each film. After the samples were allowed to swell on the surface of the agar plate at room temperature for $2 \mathrm{~h}$, films were removed from the agar and their side length $\left(L_{\text {wet }}\right)$ and weight $\left(W_{\text {wet }}\right)$ were measured. The percent swellings were calculated using the following equation:

Swelling ratio based on length $=\frac{L_{\text {wet }}-L_{\text {dry }}}{L_{\text {dry }}} \times 100$
Swelling ratio based on weight $=\frac{W_{\text {wet }}-W_{\text {dry }}}{W_{\text {dry }}} \times 100$

Where $L_{\text {wet }}$ and $W_{\text {wet }}$ are the length of a side and weight of the swollen film after $2 \mathrm{~h}$, respectively. $L_{\text {dry }}$ and $W_{\text {dry }}$ are the length of a side and weight of the original film at zero time $(16,17)$.

\section{Results}

As shown in Figure 1, samples \#1-4, prepared using a solution containing a chitosan aqueous solution, were transparent and almost free of bubbles. In contrast, white crystals were observed in sample \#5, which did not contain an aqueous chitosan solution. In addition, since this film 


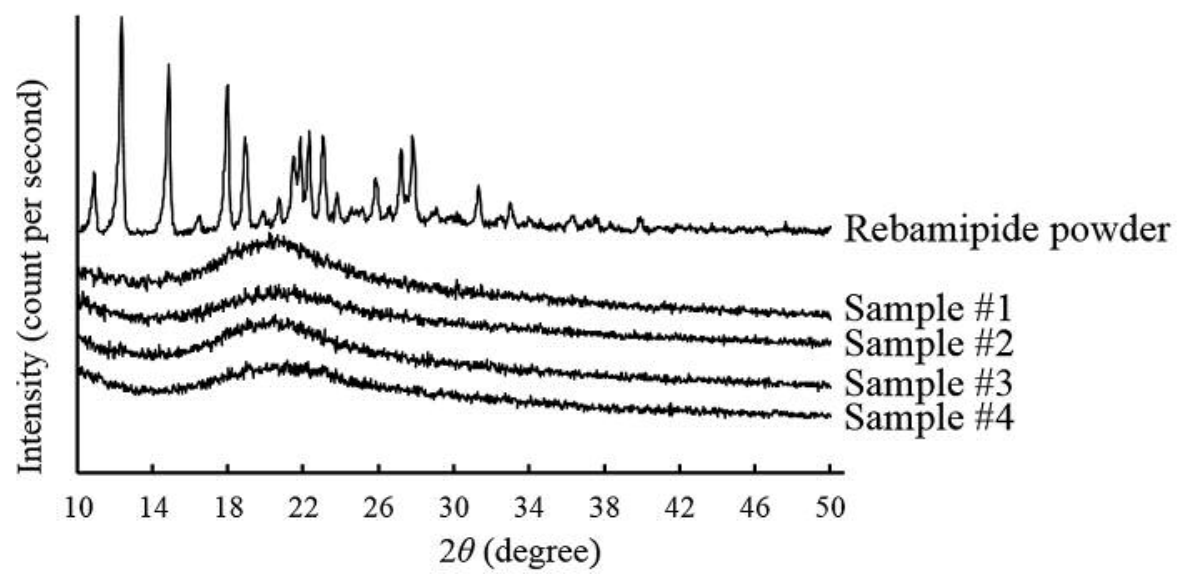

Figure 2. X-ray diffraction patterns of rebamipide powder and samples \#1-4.

could not be peeled from the silicone rubber plate, we considered that it was inappropriate as a film formulation and did not perform any further testing.

X-ray diffraction patterns of rebamipide powder and samples \#1-4 are illustrated in Figure 2. Peaks derived from rebamipide crystals were not detected, and it was confirmed that they were in an amorphous state.

Cumulative release ratios of rebamipide from rebamipidecontaining films at 0-360 min are shown in Figure 3a. After $120 \mathrm{~min}$ from the initiation of the test, there were significant differences between sample \#1 and sample \#3, and sample \#3 and sample \#4. Similarly, after $240 \mathrm{~min}$ from the initiation of the test, the release of rebamipide from the film was significantly decreased in sample \#3 as compared to samples $\# 1$ and \#4. Figure $3 \mathrm{~b}$ is an enlargement of the part from $0-60$ min in Figure 3a. Up to $30 \mathrm{~min}$ from the initiation of the test, it was confirmed that samples \#3 and \#4, which used a large amount of HPMC aqueous solution for preparation, had a large cumulative release amount of rebamipide. However, at $60 \mathrm{~min}$ after the initiation of the test, the cumulative release amount of rebamipide from sample \#3 was significantly lower than that of sample \#1, which did not include HPMC aqueous solution, and was comparable to that of sample \#2, which contained a small amount of HPMC aqueous solution. As shown in Figures $3 \mathrm{a}$ and $3 \mathrm{~b}$, samples \#1 and \#2 seemed to have little difference in their release behaviors. Therefore, to confirm the difference between these release behaviors, dissolution profiles were also individually compared using the "similarity factor, $\mathrm{f}_{2}$ ", which could be defined as follows:

$$
f_{2}=50 \times \log \left\{\left[1+(1 / n) \sum_{t=1}^{n}\left(R_{t}-T_{t}\right)^{2}\right]^{-1 / 2} \times 100\right\}
$$

Where $n$ is the sample number, $R_{t}$ and $T_{t}$ are the reference assay and test assay at time point t, respectively (18-20). The value of $f_{2}$ is in the range of 0 to 100 , and the higher the similarity between the two profiles, the higher the value of $f_{2}$, and if the value of $f_{2}$ is 50 or more, it can be concluded that there is no difference between the two profiles (19). The value of $f_{2}$ calculated from the rebamipide release profiles from sample \#1 and \#2 was 70.9, whereas that calculated from the other sample combinations did not exceed 50 (34.8-46.7).

The results of the swelling test are shown in Figures 4 and 5 . The swelling ratio was calculated by the change in length or the change in weight. In the first case, the swelling ratio of sample \#1was significantly higher than that of the other samples (Figure 4). In the second case, the swelling ratio of sample \#1 was significantly different from that of sample \#2, which was significantly different from that of sample \#3, which was significantly different from that of sample \#4 (Figure 5).

\section{Discussion}

The results of cumulative release ratios of rebamipide from rebamipide-containing films (Figure 3), it was shown that to expect sustained release by HPMC, the formulation should contain approximately $25 \%$ of HPMC aqueous solution. The X-ray diffraction patterns (Figure 2), showed that samples \#14 were all amorphous and hence it was considered that the effect of the differences in crystallinity on the release of rebamipide from the film was small. Therefore, it was suggested that the ratio of the chitosan aqueous solution and the HPMC aqueous solution in the preparation of the film had a great influence on the cumulative rebamipide release ratio.

As shown in Figure 4, films containing HPMC (sample \#2-4) had a lower length-based swelling ratio compared to 


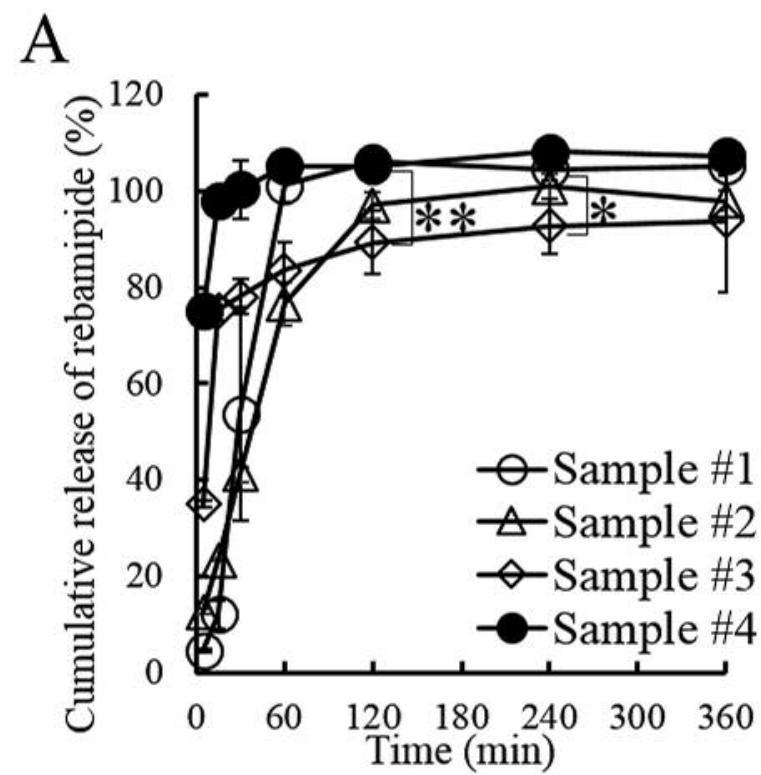

$\mathrm{B}$

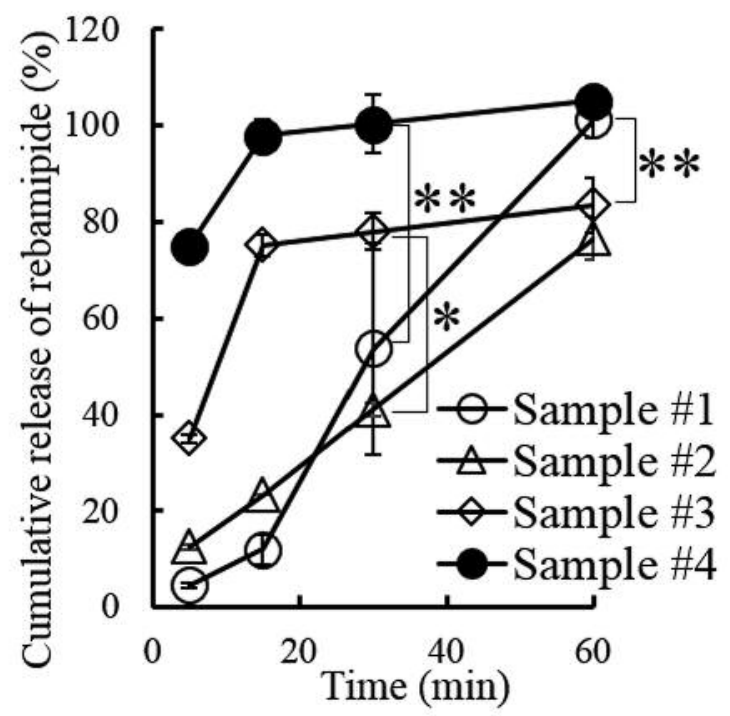

Figure 3. Cumulative release ratios of rebamipide from rebamipidecontaining films (mean \pm S.D., $n=3, * p<0.05, * * p<0.01$, Tukey's test). (A) 0-360 min. (B) 0-60 min.

sample \#1 and improved shape retention. Chitosan is a polysaccharide with an amino group and is positively charged under mildly acidic conditions. Therefore, chitosan is positively charged on agar and swells extensively due to repulsion between carbohydrate chains $(16,21)$. We presumed that HPMC interacted with chitosan and reduced this intermolecular repulsion. In sample \#1, the on weightbased swelling ratio also became large (Figure 5). The weight-based swelling ratio decreased with increasing proportion of HPMC. Films with more chitosan have greater

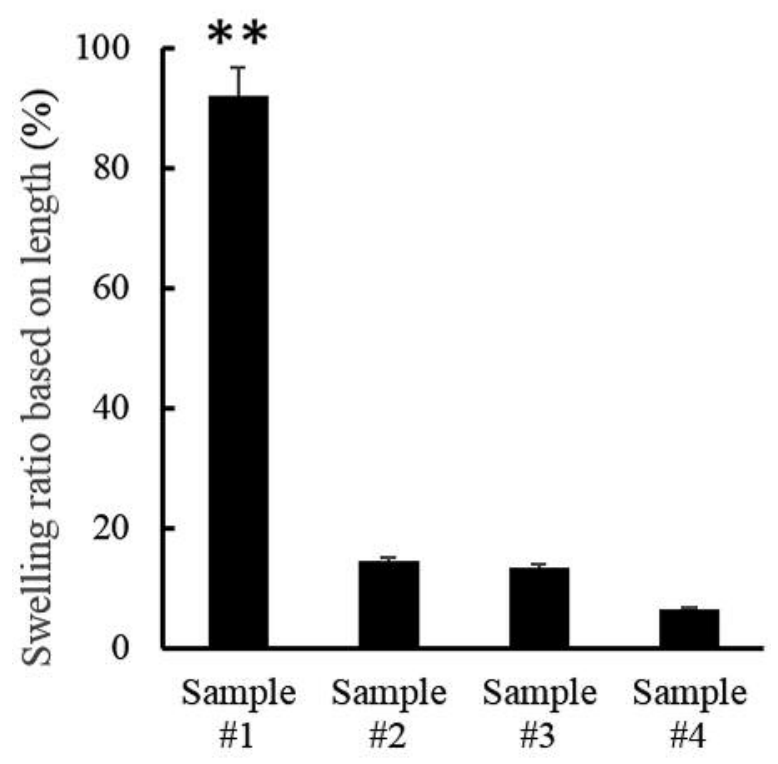

Figure 4. Swelling ratio of rebamipide-containing films based on the length of a side of the film (mean $\pm S . D ., n=3, * * p<0.01$, Tukey's test).

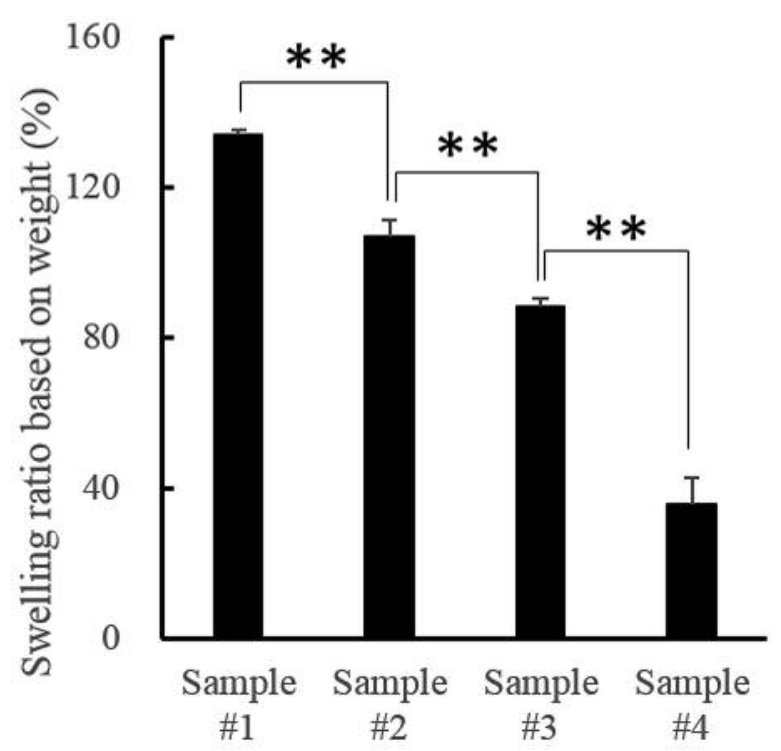

Figure 5. Swelling ratio of rebamipide-containing films based on the weight of the film (mean \pm S.D., $n=3$, **p<0.01, Tukey's test).

repulsion between molecules. Therefore, it was suggested that water molecules easily entered the interstices and the swelling ratio was increased. A large swelling ratio indicates short adhesion time to the oral mucosa and decreased retention of the therapeutic substance in the oral cavity (17, 21). We considered that a film that uses HPMC and has a low swelling ratio and can retain its shape is suitable as a formulation for oral mucositis. 
Our results showed that the addition of HPMC is useful for sustained release of rebamipide-containing films. Furthermore, it was revealed that the optimal mixing ratio of chitosan aqueous solution and HPMC aqueous solution needs to be studied because the release of rebamipide from the film in the initial stage increases when the proportion of HPMC is too high.

\section{Conclusion}

In this study, rebamipide-containing films were prepared using chitosan and HPMC. It was revealed that the mixing ratio of chitosan aqueous solution and HPMC aqueous solution affects the release behavior of rebamipide from the film. In addition, it was shown that HPMC contributed to maintaining the shape of the film. In vivo studies using a mouse model for oral mucositis induced by cancer chemotherapy $(22,23)$ will further reveal the usefulness of chitosan-HPMC films.

\section{Conflicts of Interest}

The Authors declare that they have no potential conflicts of interest related to this study.

\section{Authors' Contributions}

I. Takeuchi and C. Togo designed the study, and wrote the initial draft of the manuscript. K. Makino contributed to the analysis and interpretation of data, and assisted in the preparation of the manuscript. All Authors approved the final version of the manuscript, and agreed to be accountable for all aspects of the work in ensuring that questions related to the accuracy or integrity of any part of the work are appropriately investigated and resolved.

\section{Acknowledgements}

The Authors are grateful for the suggestions given by $\mathrm{Mr}$. T. Nakajima from Tokyo University of Science (Center for Drug Delivery Research).

\section{References}

1 Harris DJ: Cancer treatment-induced mucositis pain: strategies for assessment and management. Ther Clin Risk Manag 2: 251258, 2006. PMID: 18360600. DOI: 10.2147/tcrm.2006.2.3.251

2 Al-Ansari S, Zecha JAE, Barasch A, de Lange J, Rozema FR and Raber-Durlacher JE: Oral mucositis induced by anticancer therapies. Curr Oral Health Rep 2: 202-211, 2015. PMID: 26523246. DOI: 10.1007/s40496-015-0069-4

3 Cinausero M, Aprile G, Ermacora P, Basile D, Vitale MG, Fanotto V, Parisi G, Calvetti L and Sonis ST: New frontiers in the pathobiology and treatment of cancer regimen-related mucosal injury. Front Pharmacol 8: 354, 2017. PMID: 28642709. DOI: 10.3389/fphar.2017.00354
4 Rubenstein EB, Peterson DE, Schubert M, Keefe D, McGuire D, Epstein J, Elting LS, Fox PC, Cooksley C and Sonis ST: Clinical practice guidelines for the prevention and treatment of cancer therapy-induced oral and gastrointestinal mucositis. Cancer 100: 2026-2046, 2004. PMID: 15108223. DOI: 10.1002/cncr.20163

5 Takeuchi I, Kamiki Y and Makino K: Therapeutic efficacy of rebamipide-loaded PLGA nanoparticles coated with chitosan in a mouse model for oral mucositis induced by cancer chemotherapy. Colloids Surf. B 167: 468-473, 2018. PMID: 29723818. DOI: 10.1016/j.colsurfb.2018.04.047

6 Sun WH, Tsuji S, Tsuji M, Gunawan ES, Kawai N, Kimura A, Kakiuchi Y, Yasumaru M, Iijima H, Okuda Y, Sakai Y, Hori M and Kawano S: Induction of cyclooxygenase-2 in rat gastric mucosa by rebamipide, a mucoprotective agent. J Pharmacol 295: 447-452, 2018. PMID: 11046075.

7 Ishihara K, Komuro Y, Nishiyama N, Yamasaki K and Hotta K: Effect of rebamipide on mucus secretion by endogenous prostaglandin-independent mechanism in rat gastric mucosa. Arzneim-Forsch 42: 1462-1466, 1992. PMID: 1337697.

8 Yoshikawa T, Naito Y, Tanigawa T and Kondo M: Free radical scavenging activity of the novel anti-ulcer agent rebamipide studied by electron spin resonance. Arzneim-Forsch 43: 363-366, 1993. PMID: 8387788.

9 Arawaka T, Higuchi K, Fujiwara Y, Watanabe T, Tominaga K, Sasaki E, Oshitani N, Yoshikawa T and Tarnawski AS: 15th anniversary of rebamipide: looking ahead to the new mechanisms and new applications. Digest Dis Sci 50: S3-S11, 2005. PMID: 16184418. DOI: 10.1007/s10620-005-2800-9

10 Yasuda T, Chiba H, Satomi T, Matsuo A, Kaneko T, Chikazu D and Miyamatsu H: Preventive effect of rebamipide gargle on chemoradiotherapy-induced oral mucositis in patients with oral cancer: a pilot study. J Oral Maxillofac Res 2: e3, 2011. PMID: 24422000. DOI: 10.5037/jomr.2011.2403

11 Yokota T, Ogawa T, Takahashi S, Okami K, Fujii T, Tanaka K, Iwae S, Ota I, Ueda T, Monden N, Matsuura K, Kojima H, Ueda S, Sasaki K, Fujimoto Y, Hasegawa Y, Beppu T, Nishimori H, Hirano S, Naka Y, Matsushima Y, Fujii M and Tahara M: Efficacy and safety of rebamipide liquid for chemoradiotherapyinduced oral mucositis in patients with head and neck cancer: a multicenter, randomized, double-blind, placebo-controlled, parallel-group phase II study. BMC Cancer 17: 314, 2017. PMID: 28476132. DOI: 10.1186/s12885-017-3295-4

12 Miyazaki S, Ishii K and Nadai T: The use of chitin and chitosan as drug carriers. Chem Pharm Bull 29: 3067-3069, 1981. PMID: 7318032. DOI: $10.1248 / \mathrm{cpb} .29 .3067$

13 Takeuchi I, Takeshita T, Suzuki T and Makino K: Iontophoretic transdermal delivery using chitosan-coated PLGA nanoparticles for positively charged drugs. Colloids Surf. B 160: 520-526, 2017. PMID: 29017147. DOI: 10.1016/j.colsurfb.2017.10.011

14 Cafaggi S, Leardi R, Parodi B, Caviglioli G, Russo E and Bignardi G: Preparation and evaluation of a chitosan saltpoloxamer 407 based matrix for buccal drug delivery. J Controlled Rel 102: 159-169, 2005. PMID: 15653142. DOI: 10.1016/j.jconrel.2004.09.019

15 Takeuchi I, Shimakura K, Kuroda H, Nakajima T, Goto S and Makino $\mathrm{K}$ : Estimation of crystallinity of nifedipinepolyvinylpyrro-lidone solid dispersion by usage of terahertz time-domain spectroscopy and of X-ray powder diffractometer. J Pharm Sci 104: 4307-4313, 2015. PMID: 26461839. DOI: $10.1002 /$ jps. 24671 
16 Tanabe T, Okitsu N, Tachibana A and Yamauchi K: Preparation and characterization of keratin-chitosan composite film. Biomaterials 23: 817-825, 2002. PMID: 11771701. DOI: 10.1016/s0142-9612(01)00187-9

17 Castán H, Ruiz MA, Clares B and Morales ME: Design, development and characterization of buccal bioadhesive films of Doxepin for treatment of odontalgia. Drug Deliv 22: 869-876, 2015. PMID: 24670096. DOI: $10.3109 / 10717544.2014 .896958$

18 Pillay V and Fassihi R: Evaluation and comparison of dissolution data derived from different modified release dosage forms: an alternative method. J Controlled Rel 55: 45-55, 1998. PMID: 9795013. DOI: 10.1016/s0168-3659(98)00022-4

19 Shah VP, Tsong Y, Sathe P and Liu J-P: In vitro dissolution profile comparison - Statistics and analysis of the similarity factor, $\mathrm{f}_{2}$. Pharm Res 15: 889-896, 1998. PMID: 9647355. DOI: 10.1023/a:1011976615750

20 Malaterre V, Ogorka J, Loggia N, Gurny R: Evaluation of the tablet core factors influencing the release kinetics and the loadability of push-pull osmotic systems. Drug Dev Ind Pharm 35: 433-439, 2009. PMID: 18989838. DOI: 10.1080/03639040 802425230
21 Sudhakar Y, Kuotsu K and Bandyopadhyay AK: Buccal bioadhesive drug delivery - a promising option for orally less efficient drugs. J Controlled Rel 114: 15-40, 2006. PMID: 16828915. DOI: $10.1016 /$ j.jconrel.2006.04.012

22 Shimamura Y, Takeuchi I, Terada $\mathrm{H}$ and Makino K: A mouse model for oral mucositis induced by cancer chemotherapy. Anticancer Res 38: 307-312, 2018. PMID: 29277788. DOI: 10.21873/anticanres. 12223

23 Shimamura Y, Takeuchi I, Terada H and Makino K: Therapeutic effect of GGsTop, selective gamma-glutamyl transpeptidase inhibitor, on a mouse model of 5-fluorouracil-induced oral mucositis. Anticancer Res 39: 3201-206, 2019. PMID: 3059 1459. DOI: 10.21873 /anticanres.13098

Received November 13, 2019

Revised November 18, 2019

Accepted November 19, 2019 